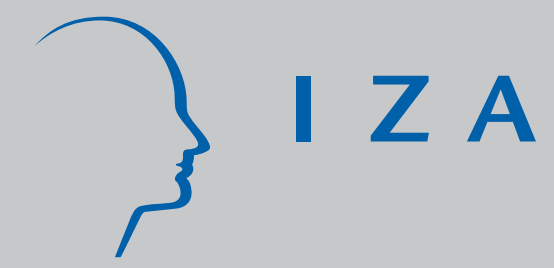

IZA DP No. 32

Work or Retirement?

Exit Routs for Norwegian Elderly

Sven-Age Dahl

Oivind Anti Nilsen

Kjell Vaage

February 1999 


\title{
Work or Retirement? Exit Routes for Norwegian Elderly
}

\author{
Svenn-Åge Dahl \\ Øivind Anti Nilsen \\ Kjell Vaage
}

Discussion Paper No. 32

February 1999

\author{
IZA \\ P.O. Box 7240 \\ D-53072 Bonn \\ Germany \\ Tel.: +49-228-3894-0 \\ Fax: +49-228-3894-210 \\ Email: iza@iza.org
}

This Discussion Paper is issued within the framework of IZA's research areas The Welfare State and Labor Markets and General Labor Economics. Any opinions expressed here are those of the author(s) and not those of the institute. Research disseminated by IZA may include views on policy, but the institute itself takes no institutional policy positions.

The Institute for the Study of Labor (IZA) in Bonn is a local and virtual international research center and a place of communication between science, politics and business. IZA is an independent, nonprofit limited liability company (Gesellschaft mit beschränkter Haftung) supported by the Deutsche Post AG. The center is associated with the University of Bonn and offers a stimulating research environment through its research networks, research support, and visitors and doctoral programs. IZA engages in (i) original and internationally competitive research in all fields of labor economics, (ii) development of policy concepts, and (iii) dissemination of research results and concepts to the interested public. The current research program deals with (1) mobility and flexibility of labor markets, (2) internationalization of labor markets and European integration, (3) the welfare state and labor markets, (4) labor markets in transition, (5) the future of work, and (6) general labor economics.

IZA Discussion Papers often represent preliminary work and are circulated to encourage discussion. Citation of such a paper should account for its provisional character. 


\section{ABSTRACT}

\section{Work or Retirement? \\ Exit Routes for Norwegian Elderly ${ }^{*}$}

In this paper we analyse early retirement pathways for Norwegian male and female workers. We apply a multinomial logit model to a data set covering more than 10500 employees, ages 56-61, in 1989. The aim is to analyse the transition to different destinations, i.e. disability pension, unemployment benefits, out of the labour force, in the period from 1989 till 1995. Both family characteristics, expected income in different end-states, and push factors, such as industry attachment and local unemployment, are important for the early retirement process. Our findings also indicate that there are several gender differences. The explanatory variables have different effects on the different exit routes for males as well as for females. We therefore reject the hypothesis that disability and unemployment are exchangeable pathways into early retirement.

JEL Classification: J26, C23, C25

Keywords: Early retirement, labour force participation

Øivind Anti Nilsen

University of Bergen

Department of Economics

Fosswinckelsgt. 6

$\mathrm{N}-5007$ Bergen

Norway

Tel.: +4755589200

Fax: +4755589210

Email: oivind.nilsen@econ.uib.no

\footnotetext{
* The data for this analysis were provided by the Norwegian Social Data Services (NSD). The paper has benefited from insightful comments from seminar participants at the Norwegian Ministry of Finance, at the Department of Economics, University of Bergen, and from participants on a workshop in Amsterdam in connection with the EU-TSER sponsored project "Schooling, Training, and Transitions". Financial support from the Norwegian Ministry of Finance and the EU-TSER project is gratefully acknowledged. The usual disclaimer applies.
} 


\section{INTRODUCTION}

In all OECD countries the proportion of elderly in the population is increasing and it will continue to do so in the years to come. At the same time, these countries have experienced a drop in the average age of retirement. Early retirement will affect the age structure of the labour force and therefore have consequences for labour costs and competitiveness. In addition, early retirement causes concern for the financing of the welfare states in the immediate future. Thus, early retirement is an important topic on the political agenda in many countries.

In Norway the number of employees over 60 years of age fell by 36000 , or $22 \%$, in the period from 1975 to 1992 (NOU 1994:2). This decline was due to reduced labour force participation among men. The labour force participation for Norwegian women, on the other hand, has increased slightly and is relatively high compared to other countries, especially among older cohorts (see Figure 1).

(Figure 1 about here.)

In Norway too the proportion of elderly is rising, and this trend will continue in the next few decades. Thus, it is important that we improve our knowledge about the determinants of retirement, both in order to improve our general understanding of the labour markets and to enable us to evaluate possible policy options.

Retirement not only involves a choice of retirement age, which is often the main theme in the retirement literature; it also involves a choice between different transition states (Boskin and Hurd, 1978; Riphahn, 1997) or retirement schemes (Haveman et al., 1988). Thus, it is desirable that we allow for the coexistence of different destination states when early retirement is analysed. In our analysis we use a discrete choice model with several destinations: disability pension, unemployment benefits, and out of the labour force. Both the disability and unemployment insurance have functioned as informal early retirement pensions in Norway, while no public early retirement scheme exists.

Aggregate figures suggest that disability benefits have been more readily granted when unemployment is rising or when particular difficulties occur in local labour markets. The inclusion of both disability and longterm unemployment as different end-states in a competing risk framework permits us to identify potential differences in the transitions from work to early retirement. This may shed light on the discussion of whether unemployment and disability are substitutable retirement pathways. In the public debate it is sometimes argued that disability retirement is over-utilised, i.e. that individuals that become unemployed are ending up in disability retirement without being truly disabled. Such practice sends the wrong signals to both the authorities 
and to economic agents. A possible consequence might be that the access to disability benefits is restricted for those who really need them (see Riphahn (1997) for a more thorough discussion).

Another question we raise in the following is whether the retirement behaviour of males and females is different. Differences may be due to gender-specific preferences regarding work or retirement. Moreover, as family characteristics such as health, earlier labour market attachment, income and wealth, etc. may vary for older men and women, it is crucial not to restrict the retirement paths of the two genders to be identical. The comparison of male and female retirement behaviour is an important part of our paper, not least because previous research on female retirement behaviour, as compared to male, is limited. Moreover, we believe that Norwegian data may be particularly suitable for the analysis of possible gender differences among older workers, since the participation rates for older females are relatively high in Norway compared to other countries.

The literature typically distinguishes between push and pull factors in retirement behaviour (e.g. Kohli and Rein, 1991). The economic-oriented pull view assumes that early exits are the result of social policies that have created attractive exit possibilities, for example, by lowering age boundaries and opening new institutional pathways. Sociological theory, on the other hand, focuses on the push factors generated by the organisation of work. This framework assumes that the process of early exit is driven by the evolution of the labour markets, especially by the high rates of unemployment, and by deeper structural features such as rationalisation and outsourcing, accompanied by the growth of subcontracting and the increased use of temporary workers. In this view, early exit takes place regardless of what institutional pathways are available, and accordingly, no social policy can stop early exit from occurring. We try to control for both push and pull factors in our analysis. Push factors are identified by local unemployment rates and workers' industry attachment, while the pull factors associated with economic incentive are captured by the expected income brought about by different early retirement schemes.

In the empirical literature, structural as well as reduced form approaches have been used. In structural models, there is a relatively clear correspondence between the theoretic microeconomic model and the empirical model. In the reduced form approach, however, the underlying structural parameters and functions in the theoretical model cannot be identified. Instead, the focus is on the impact of the relevant explanatory variables that are significant for the probabilities of ending in different end-states. We have chosen to apply the reduced form model for two reasons: first, because a structural model that embeds the theories that take into account 
both push and pull factors is difficult to construct. Second, even with a structural model, the resulting inference would probably be fragile with respect to the assumptions made when specifying the model.

We utilised the very rich KIRUT database, a database that contains detailed individual information for a random 10\% sample of the Norwegian population aged 16-67. From KIRUT we extracted more than 10000 employed individuals between 56 and 60 years of age in 1989. Transitions from work to early retirement were then registered until the end of 1995.

The remainder of the paper is organised as follows. In Section 2 we briefly review the relevant literature on retirement and position ourselves relative to the various perspectives. In Section 3 we describe institutional features of the Norwegian retirement system. The design of the study and the model specifications are presented in Section 4, and in Section 5 we describe the data and the development in the number of individuals in various end-states, together with variable construction. Section 6 contains empirical results and discussion, and concluding remarks are given in Section 7.

\section{PREVIOUS RESEARCH}

Most of the research on (early) retirement has previously been limited to the United States, though research on early retirement in Europe is increasing in volume (see, for instance, the bibliography given in OECD (1998)). According to Ruhm (1990a), research examining the labour force behaviour of older workers, at least in the United States, has concentrated on six themes: health, mandatory retirement, social security, private pensions, earnings and wealth, and partial retirement. Our study focuses on social security and earnings, controlling for a rich set of background covariates. ${ }^{1}$ Contrary to the vast majority of the previous contributions, however, we analyse both male and female retirement behaviour. The female labour force participation rates are high in the Nordic countries. Thus, data from these countries seems particularly suitable for the analysis of potential gender differences. Examples of Nordic research include Wadensjö (1996), which comprises several studies of labour force greying and exits from the labour market in the Nordic countries. Pedersen and Smith (1996), using a competing-risk model with three different end-states, find that there are significant gender differences in the decision to retire early in Denmark. These results may be contrasted with those of Lilja

\footnotetext{
${ }^{1}$ Unfortunately, we have no available data on individual wealth.
} 
(1996), who found that the propensity for early exits does not differ significantly between males and females.

However, Lilja's study, based on Finnish data, may suffer from the fact that potential gender differences are meant to be picked up by a single gender-specific intercept only. Assuming that all coefficients are the same except for the gender dummy implicitly requires that all the determinants of early retirements affect the retirement choice similarly for the two genders.

One of the goals of this study is to compare the determinants of disability and unemployment as early retirement pathways. Other researchers have also addressed this topic. Riphahn (1997) tests for possible substitutability between unemployment and disability retirement in Germany. The hypothesis that disability retirement and unemployment are substitutes is rejected. The critical determinants of transitions into disability and into unemployment, such as individual health and aggregate unemployment, clearly have different effects on the two forms of exit from employment. Similarly, Woittiez et al. (1994) find that the characteristics of both individuals and jobs are different dependent on the exit route the individuals use. Note, however, that both studies cover male retirement only.

Hernæs et al. (1997) is, to our knowledge, the only microeconometric analysis based on Norwegian data. Their prime motivation, however, was to model the likely effects of a privately negotiated early retirement scheme (“AFP”). The study provides no test for substitutability between retirement paths, and gender difference is restricted to a gender dummy only.

\section{PATHWAYS TO EARLY RETIREMENT IN NORWAY}

The standard pension age in Norway is 67 years of age on the condition that a person gives up the right to keep a specific job. The compulsory retirement age is 70 . Some professions have a lower pension age and some are fixed by law. ${ }^{2}$ There is no public early retirement scheme in Norway. However, as in several other countries, institutional arrangements that were originally constructed for other purposes, unemployment pension and disability benefits, have been used as pathways of early retirement.

\footnotetext{
${ }^{2}$ For pilots and divers the retirement age is 55; for sailors, fishermen, lumberjacks and cabin crew (except pilots) 60 years; professional drivers 62 years; and for nurses, offshore workers, travelling salesmen, miners, reindeer shepherds, driving instructors, crane operators, excavator drivers, bulldozer drivers and insurance salesmen 65 years.
} 
Until the early 1990s the entitlement conditions for disability insurance in Norway were liberal, and labour market conditions were a factor in the disability assessment. Before receiving disability pension, sickness insurance is usually paid for one year, and a subsequent period in a rehabilitation program is required. To qualify for disability pension, a person must demonstrate that his/her ability to earn an income has been permanently reduced by at least $50 \%$. In addition, unemployment insurance is paid for a longer period than normal to older people. Persons who become unemployed when they are 60.5 years old can receive unemployment insurance until they reach the standard pension age of 67 years.

The replacement rate for disability pension is about $62 \%$, but in order to increase the employees' incentives to apply, employers in many firms have paid a small company pension in addition to the state paid disability pension, thereby increasing the replacement rate up to $80 \%$. The standard replacement rate for unemployment is $62 \%$. Also for this retirement scheme, several firms have paid a small company pension to employees who agreed to be "voluntarily" laid off, which increases the replacement rate substantially.

There are several non-public early retirement schemes in Norway, and these have been introduced for several reasons. First, several firms were overstaffed and needed a downsizing option in addition to unemployment insurance. Elderly employees are protected by specific seniority and age-related conditions in the Norwegian Act on the Working Environment. But since laying off skilled employees in their 30s and 40s has obvious detrimental effects, early retirement of elderly employees has been preferred, even though it is often costly. A second reason for introduction of non-public retirement schemes is that unions and employees are more likely to accept downsizing through early retirement than layoffs. A third reason is that, since unions and employees look upon early retirement as a "welfare good", such schemes are in demand, especially since public early retirement schemes are non-existent. In other words, it is not only the employees who are pushed out of the firms by the employers, but also the employers who are encouraged by the employees and their unions to set up early retirement schemes. In addition, several private and state-owned companies have established permanent or temporary early retirement schemes. These schemes are fully paid by the company and employees down to the age of 57 years are offered early retirement. Most schemes, however, have a minimum pension age between 60 and 64 years. The replacement rate varies between 60 and $90 \%$.

A privately negotiated early retirement scheme ("Early Retirement Pension Agreement - AFP") came into effect from 1 January $1989 .^{3}$ The pension age in the scheme has been gradually reduced over the years, and

\footnotetext{
${ }^{3}$ AFP covers employees organised in labour unions in firms that are organised in the Norwegian Employers' Federation (NHO).
} 
has been set at 62 as of 1 March 1998. The use of the scheme has increased as the retirement age has been reduced, as the replacment rate has been improved (in 1992) and as knowledge of the scheme has improved. This early retirement scheme is supported financially by the state (40\%), and represents an entitlement for those with at least ten years of social security contributions, and for those whose pension income is at or above a certain minimum. The pension is the same as the full pension entitlement, but is less favourably treated under income taxation than a full old-age pension. The replacement rate for AFP varies between 50 and $60 \%$. Morover, a new trend is that some firms pay such a company pension to former employees in addition to the AFP pension.

Ideally, private early retirement schemes and AFP, would be included as additional pathways in our study. However, data on private schemes are not available. The National Insurance Administration has some data on AFP retirees, but mainly from 1995 and onward.

Finally, in contrast to many other countries, partial retirement and bridge jobs play a minor role in the transition from work to retirement in Norway, and are not as important as they are, for example, in the United States (Ruhm, 1990b).

\section{MODEL SPECIFICATION}

Our model aims to answer a simple empirical question: What factors affect the probability of being observed in the end states of disability, unemployment, out of the labour force, and work in December 1995, conditional on being in the state of work in January 1989? Formally, we assume that individual $i$ chooses alternative $j$ if the associated utility, $U_{j i}$, is the highest of all $J$ alternatives. For each individual we define a latent variable, $Y_{j}^{*}$, that denotes the change in utility of moving from the state work in 1989 to early retirement in 1995 . The (change in) utility is determined by a vector of observable variables, $\mathbf{x}$, including expected income in the different states, personal characteristics, labour market conditions, etc., and a stochastic error term, $\varepsilon_{j}$ :

$$
Y_{j}^{*}=U_{j, 95}-U_{w o r k, 89}=\mathbf{b}_{\mathbf{j}}^{\prime} \mathbf{x}+\varepsilon_{j} \quad j=0,1,2,3
$$


What we observe are the discrete choices,

$$
Y_{j i}=\left\{\begin{array}{l}
1 \text { if } Y_{j i}^{*}>0 \\
0 \text { if } Y_{j i}^{*} \leq 0
\end{array}\right.
$$

where the probability of choosing state $j$ can be expressed as:

$$
\operatorname{Prob}\left(Y_{j i}=1\right)=\operatorname{Prob}\left(Y_{j i}^{*}>0\right)=\operatorname{Prob}\left(\varepsilon_{j i}>-\mathbf{b}_{\mathbf{j}}^{\prime} \mathbf{x}_{\mathbf{i}}\right)
$$

We assume that $\varepsilon_{j i}$ is type I extreme-value and independently and identically distributed across alternatives and individuals. The estimations can then be implemented through the multinomial logit model:

$$
\operatorname{Prob}\left(Y_{i}=j\right)=\frac{e^{\mathbf{b}_{j}^{\prime} \mathbf{x}_{i}}}{\sum_{j=0}^{3} e^{\mathbf{b}_{j}^{\prime} \mathbf{x}_{i}}}
$$

In Section 6 we focus on competing risks, and report the marginal effects found by differentiating equation (1):

$$
\frac{\partial P_{j i}}{\partial \mathbf{x}_{\mathbf{i}}}=P_{j i}\left[\mathbf{b}_{\mathbf{j}}-\sum_{k=0}^{3} P_{k i} \mathbf{b}_{\mathbf{k}}\right]
$$

where $P_{j i}$ equals $\operatorname{Prob}\left(Y_{i}=j\right)$ as defined in equation (3). We allow all the covariates to have various impacts on the flow to different states for the two genders by doing the analysis separately for males and females.

The analysis is mainly descriptive and the results from our reduced form model cannot be given a clear structural interpretation. Some of our regressors may be plagued by potential endogeneity problems due to selection processes on unobserved background characteristics. Thus, the estimated marginal effects of some of the explanatory variables may reflect both the impact of the variables themselves, and potential unobserved innate 
characteristics. However, with due caution in interpretation, our analysis does identify factors that affect the probability of entering the different states.

\section{DATA}

\subsection{Data Sources}

The analysis draws on data from the KIRUT database. ${ }^{4}$ The base contains detailed individual information on socio-economic background, labour market participation, and social insurance payments for a random $10 \%$ sample of the Norwegian population aged 16-67 (the total sample exceeds 300000 individuals).

Our sample includes observations of individuals born between 1929 and 1933 who occupied a job on 1 January 1989. ${ }^{5}$ The sampled individuals were followed until the end of 1995. After excluding individuals with missing variables during the sample period, we end up with a final sample of 10512 individuals, 5603 males and 4909 females.

All individuals in the final sample were classified into one of four groups based on their labour market status in 1995. By construction, we are working with absorbing states. In this way, we avoided the problems of round tripping, i.e. individuals moving in and out of the different states in the interim period. The classification procedure for the different end-states was as follows: First, we restricted the group of disabled to include individuals who were more than $50 \%$ disabled as of 31 December 1995 . Second, we were only interested in individuals with long-term unemployment, who stayed unemployed throughout our period of observation. Thus, we ignored unemployment spells shorter than 6 months. Consequently, the unemployed were defined as those who were registered as job seekers 31 December 1995 and whose unemployment spell started before July 1995 . Note that we let disability "overrule" both unemployment and employment. For instance, we let an individual with an unemployment spell starting before a period of disability be classified as disabled. Hence, this individual's transition from work to disability was at the starting point of the disability spell. ${ }^{6}$ Finally,

\footnotetext{
${ }^{4}$ KIRUT is a Norwegian acronym that roughly translates to "Clients into and through the Social Insurance System".

${ }^{5}$ We have chosen the oldest cohort to be the 1929 cohort. These individuals will be between 65 and 66 years old in our last sample year; they are thus not entitled to an old-age pension.

${ }^{6}$ This ranking was chosen since we consider the quality of the disability data to be more reliable than that of the unemployment data.
} 
individuals that were not registered as either worker, disabled or unemployed were defined as out of the labour force. Note that in the latter group, out of the labour force, are individuals who have retired due to private or firm-provided early retirement schemes, self-employment and individuals that drop out of the labour force for other reasons. As a consequence, the out of labour force is a heterogeneous group, and care should be taken when interpreting the empirical results for this group.

The point of transitions are the start of the disability spell, the starting point of the unemployment spell, and the last day in the employers' register for the disabled, unemployed, and the individuals who leave the labour force, respectively.

\subsection{Explanatory variables}

The time varying explanatory variables were measured at the point of transition. The family relevant variables are: married, unmarried, widow (or widower), divorced, children ( $=1$ if children were under age 18, 0 otherwise). The probability of moving from one state to another may also be a function of age, so five age dummies, based on individuals' age in 1995, were included. Educational level, measured in number of years, is assumed to affect the probability of transition to different states. Being a civil servant may also be of importance for the choice of retirement pathways, due to significant job protection in the governmental sector.

We have incorporated three different income variables in our analysis. When these income variables are included, we implicitly assume that the individuals choose among expected income streams in different states. Of course, we can only observe the income in the actual state. However, by using the relevant rules for the benefits and pensions in different states, we are able to construct potential incomes in the end-states. All the various income variables are based on the income previous to the retirement year. Income as employed is equal to the income when an individual was working. Income as unemployed in Norway is $62.4 \%$ of income the previous year up to approximately NOK 240000 (in 1990 prices). For incomes higher than NOK 240000 , unemployment benefits are constant. The last income variable, income as disabled, is based on age and pension points earned. ${ }^{7}$ Income as disabled is approximately $62 \%$ of work income. Spouse income is also included together with a dummy variable indicating whether the spouse is eligible for old-age pension, or whether s/he receives rehabilitation and/or disability pensions $(1=$ old-age pensioner or benefit receiver $)$. By including these

\footnotetext{
${ }^{7}$ See for example Bratberg (1996, p. 61) for details.
} 
two variables, we hope to tell whether the "added worker" effect or "assortative mating" are present. ${ }^{8}$ All income variables (income as employed, unemployed and as disabled, and spouse income) are measured in NOK 10000 (1990 prices). ${ }^{9}$

The timing and magnitude of business cycles may vary between industries. Thus, the transition to early retirement is likely to depend on the industry in which an individual works. To control for such effects, we included six industry dummies in the model. Finally, we included some characteristics of the local municipality in which an individual resides. Residence density measures the share of the population in a local municipality that lives in urban areas $(0-9$ (dense) $)$. Distance to centre is a categorical variable that takes account of distance to larger central areas or cities (categories 1-7 (close)). The unemployment ratio is the ratio between unemployed and employed in the local municipality.

\subsection{Development in the number of individuals in various end states}

The number of persons in various end-states, is shown in Figure 2, and in more detail in Table 1.

(Table 1 and Figure 2 about here.)

The number of new persons receiving disability pension reaches a peak in 1991/1992 and then declines. This decline is probably the result of the tightened eligibility criteria (medical conditions) introduced in 1991. We can also observe a shift in the number of unemployed in 1992-93. The likely explanation is an improved Norwegian economy and decreasing national unemployment rates. The figures also suggest that females have lower unemployment rates than males (measured as the ratio between the aggregate number of unemployed individuals and the overall number of individuals), and correspondingly, are more inclined to end up as disabled. This latter pattern may be due to the fact that females are over-represented in the public sector relative to males and that job protection in the governmental sector is much better relative to the private sector.

\subsection{Descriptive statistics}

The descriptive statistics of the explanatory variables are given in Table 2 .

(Table 2 about here.)

\footnotetext{
${ }^{8}$ The "added worker" effect describes a behaviour where the labour supply increases when the spouse's income is reduced or disappears.

${ }^{9}$ NOK $12 \approx £ 1$.
} 
The statistics show that married men are likely to stay active in the labour market, while the occurrence of married women is highest among the unemployed. This finding, together with the evidence that spouse income is highest for unemployed women, may indicate that the "added worker" effect is a prevalent phenomenon among women. In addition, education is important for staying employed. Finally, the figures suggest that civil servants have a low probability of becoming unemployed. This is probably due to the relatively good job protection in the governmental sector.

All the (expected) income variables are higher for the unemployed males relative to those who end up as disabled. For females, the opposite pattern is true. These income gender differences are hard to explain. The differences may be due to some kind of selection effects. However, the occurrence of part-time jobs is greater among females than males in Norway, and this may affect females' pension rights and unemployment benefit rights and, consequently, their early retirement pathways.

According to our industry classification, most males are found in the manufacturing and construction industry, while women are over-represented in education and health. Among the unemployed, most men are recruited from manufacturing and construction, while unemployed females come from the same industry, in addition to sales, hotel and sanitary industries. All these industries are sensitive to the overall business cycles, and this may explain the high incidence of unemployed individuals from these sectors.

\section{RESULTS}

The results from the multinomial logit model, reported as marginal effects, are given in Tables 3 and 4 (males and females, respectively).

(Tables 3 and 4 about here.)

We focus on the transitions from employment to disability and unemployment, respectively. The state out of labour force, reported in the third column, covers individuals that leave the labour force for all other reasons than disability and unemployment and is, accordingly, hard to evaluate. In the interest of completeness, we also report the model estimates for the probability of staying in the labour force (at the right-most column of the tables) without commenting on these findings.

Several individual characteristics appear to have gender-specific impact on the retirement decision. Table 4 reveals that living single reduces the probability of early retirement for the female individuals. There is 
no such effect for males in Table 3; on the contrary, being divorced significantly increases the probability of retiring in the form of unemployment. In a time where family patterns are about to change in the direction of more and more people living single-especially for the younger cohorts - these results might have important implications. As these cohorts become older, we expect, all other things being equal, marital status to prevent early retirement for females, while these effects are absent, or even opposite, for males.

Age is an important determinant for the transition to disability and unemployment for males, but it appears to be marginally less important for females. Education seems to be a good form of insurance, particularly against disability, but also against unemployment. This holds for both genders. Being a civil servant does not affect the probability of entering disability. It is, on the other hand, a remarkably good predictor for not becoming unemployed. This is probably due to few layoffs and the high degree of job protection for this occupational group.

Moving to the income variables, we assume that an increase in (expected) earnings increases the probability of staying in the labour force and, thus, reduces the probability of transition to the non-labour states. This hypothesis can not be rejected, except in the case of female unemployment. The effect is strongest for disability, and stronger for women than for men. This might be a "pure" gender effect. But it may also stem from the fact that women typically work more part-time than men, and that they are over-represented in lowwage branches since, at the margin, it is plausible that labour income means more for individuals sharing these characteristics.

An increase in unemployment benefits is assumed to have a positive (own) effect on transition to unemployment retirement, and a negative (cross) effect on transition to disability retirement. None of the relevant coefficients are, however, precisely estimated. The expected level of disability pensions has, on the other hand, a sizeable effect on the probability of entering disability retirement. Once again, the response is strongest for women. There is, however, no measurable cross effect on female unemployment. For men, the cross effect is significantly positive, which is counter-intuitive.

A possible explanation for the difference in response from the two non-labour income variables might be the following: Employees may rightly assume that disability is an absorbing state. Many individuals experiencing unemployment, on the other hand, regard it as a transitory state, from where they, eventually, hope to return to work. This is so even if a substantial fraction of this age group end up as unemployed in the years remaining before the old-age pension. Disability might therefore be more of a conscious retirement choice than unemployment, and the benefits level accordingly more important. 
As regards the effect of spouse income for males, there seems to be a pattern in which higher spouse income increases the probability of staying employed and reduces the probability of getting out of the labour force. In contrast, the spouse benefit receiver dummy-variable is negative in all exits from work, which may be looked upon as an "added worker" effect. The pattern of the latter variable is the same for females. However, for females, there is a negative and significant effect of increased spouse income on the transition to disability. Hence, the overall effect of spouse characteristics is it is hard to derive from the present results.

In the estimations we control for employment in six different industries, with manufacturing as the base category. The most striking finding is that being employed in the manufacturing sector strongly increases the probability of unemployment retirement for males. The number of females employed in this sector is relatively low, which probably explains the lack of such a finding for this group. Furthermore, working in the education and health sector represents strong protection against unemployment, the explanation probably being the same as for civil servants. With two exceptions there is no correlation between sectors and the probability of entering disability retirement, at least at our level of aggregation. ${ }^{10}$

Finally, we control for some local municipality characteristics. The distance to centre variable is significantly negative for the disabled only (males and females). This means that individuals living in more central areas are less likely to end up as disabled. The sign and significance for the residence density are less clear. As expected, the local unemployment rate turns out to have sizeable effects on the probability of transition into unemployment, particularly for males. There is also a positive (but insignificant) correlation between local unemployment and transitions into disability, indicating that disability pensioning is used as a labour market instrument for this age group.

To address the question of whether disability and unemployment are exchangeable pathways into early retirement, we test whether the determinants have identical effects on the probability of entering different states. More precisely, we perform Wald tests to evaluate whether the coefficients of the competing risk are significantly different from zero. We start by testing the hypothesis $\beta^{\text {Disability }}=\beta^{\text {Unemployment }}$, where $\beta$ is a vector of all the marginal effects in each state. All the different states are significantly different. For instance, the $\chi^{2}$ test value for $\beta^{\text {Disability }}=\beta^{\text {Unemployment }}$ is 115.90 for males and 113.96 for females (degrees of freedom = 23). In Table 5, we report results from testing the hypothesis of pairwise equality of the marginal effects in

\footnotetext{
${ }^{10}$ The two exceptions are the transport and communication sector for males and the agriculture and fishery sector for females.
} 
each state. We find that the importance of education is significantly different in the two states, for both genders. When we find the joint significance of the industry dummies to be significantly different, this may be due to variation in the business cycles for different industries. Note, however, that the importance of the local unemployment rate is the same for the two end states.

Special attention should be paid to the income variables. Does a marginal increase in the disability pensions increase the probability of ending in the disability state more than a corresponding effect on unemployment from an increase in the unemployment benefits? To answer this question we test the following

null hypothesis; $\beta_{\text {disability pension }}^{\text {Disabily }}=\beta_{\text {unemployment benefit }}^{\text {Unemployment }}$. With the results from Tables 3 and 4 in mind, it comes as no surprise that the hypothesis is strongly rejected for both genders.

The findings described above indicate that disability benefits and unemployment are not substitutable end states.

\section{DISCUSSION AND CONCLUDING REMARKS}

Over the period 1972-95 Norwegian men aged 16-74 years have reduced their participation rate from $78.1 \%$ to 75.2\%. The female participation rate however, has increased from $44.7 \%$ in 1972 to $64.9 \%$ in 1995 . This increase stems mainly from younger women. Thus, the labour attachment for males and females may, at first glance, seem to be growing more equal. As a consequence, it is important that we ask whether younger women will adopt men's retirement pattern as they grow older. Our micro evidence suggests that there may be several reasons why this will not be the case.

The modern family structure with numerous single-person households appears to have a positive impact on female the participation rate, while this is not the case for male individuals. Moreover, increasing age is of less importance for female than for male retirement. Older female cohorts have lower average education than males; but this is changing rapidly, and younger women in Norway now take more education than men. With the great importance of education for the transits to different states, the implication may be increased labour force participation among women in the oldest cohorts in the years to come. Women also show a slightly greater response to changes in labour income than men. A pronounced objective for trade unions and the government is to increase women's wages relative to men. To the degree that this wage increase effort is succesful, this will improve the female labour market attachment relative to males. While employment in manufacturing and construction is decreasing, it is increasing in service industries where women work, such as 
for example, health and education. Compared to working in manufacturing and construction, employment in other industries means less use of disability pension and unemployment. Moreover, even if unemployment happens to an individual, our estimates (of the effect of local unemployment) indicate that women will be less likely to end up in unemployment retirement than is the case for men. All these findings indicate that the propensity to retire early will be lower for females than for males in the years to come.

There appear to be both push and pull factors in action in our material. Push factors, identified as unemployment rate and industry variables, have significant effects on early retirement. The unemployment rate increases the probability of retirement into both disability pension and unemployment for both men and women. As expected, the push to unemployment is less important in other industries than manufacturing and construction. In the other industries, the push is towards going out of the labour force, especially for women. Although the results from the income variables are mixed, the pull factors, labour and non-labour income, are in most cases of importance for transitions to different destination states for both genders. Nevertheless, given the importance of the push factors, substantial changes in the pull factors have to be undertaken if the goal is to reverse the early retirement trend.

Finally, our findings indicate that most of the explanatory variables have clearly different effects on the two forms of exit. Thus, disability and unemployment are not to be regarded as substitute pathways to early retirement for either males or females. 


\section{REFERENCES}

Boskin, Michael J. and Michael D. Hurd, 1978; “The Effect of Social Security on Early Retirement.” Journal of Public Economics, Vol. 10, pp. 361-377.

Bratberg, Espen, 1996; Incentives in Social Insurance. Ph.D. Dissertation. Bergen: Department of Economics, University of Bergen.

Haveman, Robert, Barbara Wolfe and Jennifer Warlick; "Labour Market Behavior of Older Men. Estimates from a Trichotomous Choice Model.” Journal of Public Economics, Vol. 36, pp. 153-175.

Hernæs, Erik, Marte Sollie and Steinar Strøm, 1997; Økonomiske betingelser og pensjonsbeslutning. SNF-report 37/97. Bergen: Foundation for Research in Economics and Business Administration (SNF).

Kohli, Martin and Martin Rein, 1991; “The changing balance of work and retirement." In Martin Kohli, Martin Rein, Anne-Marie Guillemard and Herman van Gunstern (eds.): Time for retirement. Comparative Studies of Early Exit from the Labour Force. Cambridge: Cambridge University Press.

Lilja, Reija, 1996; “Microeconomic Analysis of Early Retirement in Finland.” In Eskil Wadensjö (ed.): Leaving the Labour Market Early in the Welfare State.

NOU 1994: 2 Fra arbeid til pensjon.

OECD, 1998; The Transition from Work to Retirement. OECD Social Policy Studies No. 16. Paris: OECD.

Pedersen, Peder J. And Nina Smith, 1996; “A Duration Analysis of the Decision to Retire Early.” In Eskil Wadensjö (ed.): Leaving the Labour Market Early in the Welfare State.

Riphahn, Regina T., 1997; “Disability retirement and unemployment - substitute pathways for labour force exit? An empirical test for the case of Germany." Applied Economics, Vol. 29, 99. 551-561.

Ruhm, Christopher J., 1990a; “Determinants of the Timing of Retirement.” In Peter B. Doeringer (ed.): Bridges to Retirement. Older Workers in a Changing Labour Market. Ithaca, NY: ILR Press.

Ruhm, Christopher J., 1990b; “Bridge Jobs and Partial Retirement.” Journal of Labour Economics, Vol. 8, pp. 482-501. Wadensjö, Eskil, 1996; The Nordic Labour Markets in the 1990's. North-Holland, Amsterdam: Elsevier.

Wadensjö, Eskil, 1996; The Nordic Labour Markets in the 1990s. North-Holland, Amsterdam: Elsevier.

Woittiez, I., M. Lindeboom and J. Theeuwes, 1994; "Labour Force Exit Routes of the Dutch Elderly; A Discrete Choice Model". In L. Bovenberg (ed.): The Economics of Pensions; The ase of the Netherlands. Rotterdam: OCFEB; Research Centre for Economic Policy, Erasmus University Rotterdam, pp. 1-12. 


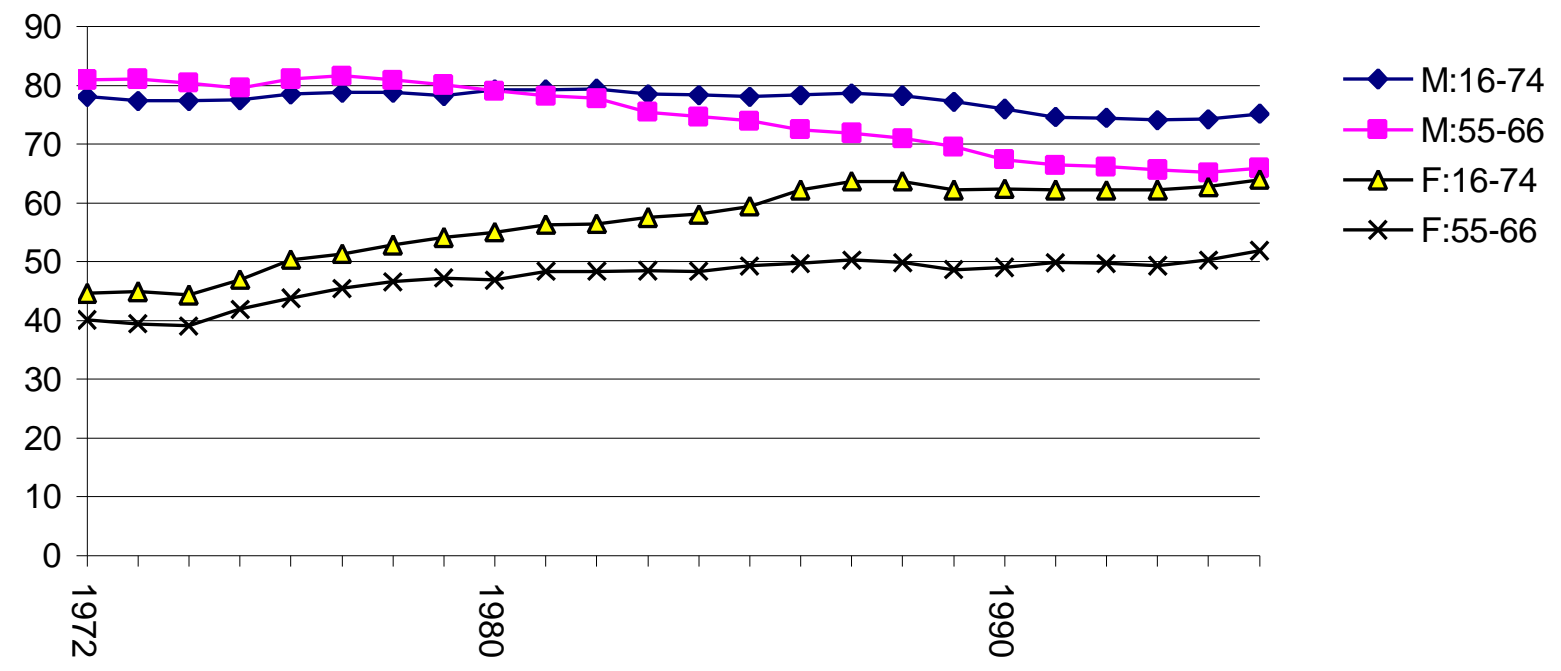

Figure 1: Participation rates for elderly, males (M) and females (F) 


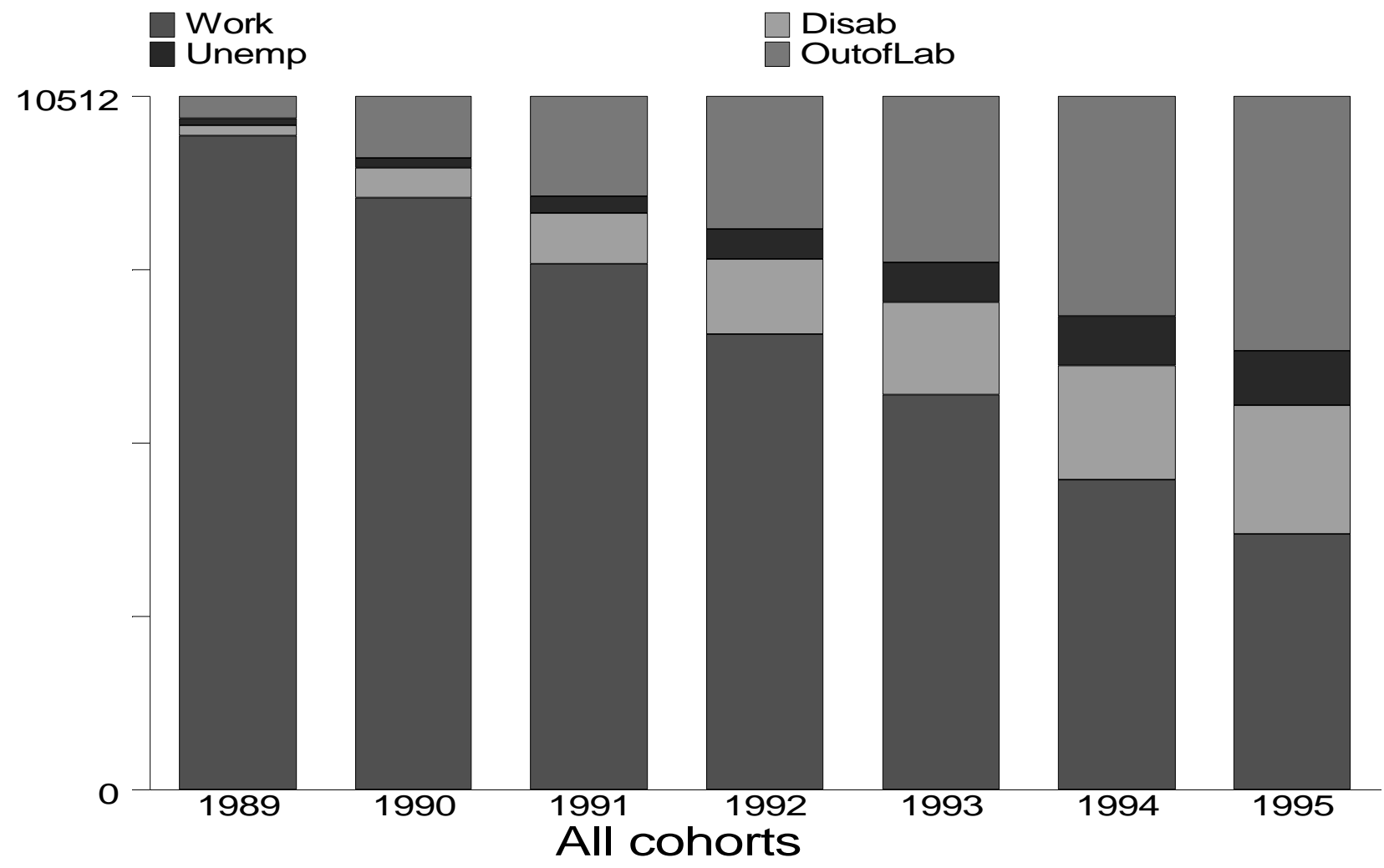

Figure 2: Inividuals in various end states, Accumulated. 


\begin{tabular}{|c|c|c|c|c|c|c|c|c|}
\hline $\begin{array}{l}\text { MALES } \\
\text { State } \\
\text { Year }\end{array}$ & \multicolumn{2}{|c|}{ Disability } & empl & & \multicolumn{2}{|c|}{$\begin{array}{l}\text { Out of } \\
\text { labour }\end{array}$} & \multicolumn{2}{|c|}{ Work } \\
\hline 1989 & 60 & (60) & 42 & (42) & 180 & (180) & -282 & $\begin{array}{l}(5603) \\
(5321)\end{array}$ \\
\hline 1990 & 146 & (206) & 29 & (71) & 298 & (478) & -473 & (4848) \\
\hline 1991 & 164 & (370) & 71 & (142) & 320 & (798) & -555 & (4293) \\
\hline 1992 & 241 & (611) & 127 & (269) & 268 & (1066) & -636 & (3657) \\
\hline 1993 & 143 & (754) & 125 & (394) & 284 & (1350) & -552 & (3105) \\
\hline 1994 & 190 & (944) & 99 & (493) & 436 & (1786) & -725 & (2380) \\
\hline 1995 & 118 & (1062) & 40 & (533) & 272 & (2058) & -430 & (1950) \\
\hline
\end{tabular}

\begin{tabular}{|c|c|c|c|c|c|c|c|c|}
\hline $\begin{array}{l}\text { FEMALES } \\
\text { State } \\
\text { Year }\end{array}$ & Dis & & empl & & & & & \\
\hline & & & & & & & & (4909) \\
\hline 1989 & 112 & (112) & 56 & (56) & 163 & (163) & -331 & (4578) \\
\hline 1990 & 130 & (242) & 25 & (81) & 305 & (468) & -460 & $(4118)$ \\
\hline 1991 & 151 & (393) & 36 & (117) & 255 & (723) & -442 & $(3676)$ \\
\hline 1992 & 140 & (533) & 59 & (176) & 238 & $(961)$ & -437 & (3239) \\
\hline 1993 & 112 & $(645)$ & 44 & $(220)$ & 207 & (1168) & -363 & $(2876)$ \\
\hline 1994 & 129 & (774) & 44 & (264) & 383 & (1551) & -556 & (2320) \\
\hline 1995 & 124 & (898) & 24 & (288) & 254 & (1805) & -402 & (1918) \\
\hline
\end{tabular}

Table 1. Individuals in various end states, by gender. Accumulated numbers in parentheses 


Individual characteristics
Married
Unmarriec
Widow(er)
Divorced
children [1=Yes
Age 61
Age 62
Age 63
Age 64
Age 65
Education [years]
Civil Servan
Income as
Employed [NOK 10 000]
Unemployed [NOK 10 000]
Disabled [NOK 10 000
Spouse characteristics
Spouse income [NOK 10 000]
(if married) [NOK 10 000
Spouse benefit receiver [1=Yes]
(if married) [1=Yes
Industries
Agri.+Fish
Manu.+Constr
Sales, Hotel, Sanitary
Transport, Commun
Dwellings, Financ
Education, Health
Local municipality
Residence density
Distance to center
Unempl. Rate
Nbr. of observations

Table 2.
Males

Disability

\section{employmentabour force}

\begin{tabular}{rrrr}
\hline $79.3 \%$ & $78.6 \%$ & $82.1 \%$ & $84.6 \%$ \\
$7.6 \%$ & $7.1 \%$ & $5.7 \%$ & $5.2 \%$ \\
$4.5 \%$ & $3.2 \%$ & $4.2 \%$ & $4.4 \%$ \\
$8.6 \%$ & $11.1 \%$ & $8.1 \%$ & $5.8 \%$ \\
0.03 & 0.04 & 0.05 & 0.05 \\
$16.3 \%$ & $16.3 \%$ & $17.9 \%$ & $26.5 \%$ \\
$20.2 \%$ & $14.6 \%$ & $18.3 \%$ & $25.6 \%$ \\
$22.4 \%$ & $20.6 \%$ & $19.9 \%$ & $19.8 \%$ \\
$20.5 \%$ & $25.7 \%$ & $22.7 \%$ & $16.3 \%$ \\
$20.6 \%$ & $22.7 \%$ & $21.2 \%$ & $11.7 \%$ \\
9.7 & 9.7 & 10.7 & 11.0 \\
$8.9 \%$ & $0.8 \%$ & $15.1 \%$ & $19.7 \%$ \\
& & & \\
18.0 & 19.4 & 20.7 & 21.9 \\
10.2 & 10.7 & 10.7 & 11.0 \\
10.1 & 10.5 & 10.7 & 10.4 \\
& & & \\
6.4 & 6.2 & 6.7 & 7.3 \\
7.7 & 7.6 & 7.9 & 8.4 \\
$18.0 \%$ & $15.0 \%$ & $14.0 \%$ & $23.9 \%$ \\
$22.7 \%$ & $19.1 \%$ & $17.1 \%$ & $28.3 \%$ \\
& & & \\
$3.2 \%$ & $1.3 \%$ & $2.1 \%$ & $3.6 \%$ \\
$51.5 \%$ & $72.0 \%$ & $40.2 \%$ & $41.2 \%$ \\
$13.3 \%$ & $12.4 \%$ & $9.8 \%$ & $13.3 \%$ \\
$8.1 \%$ & $2.8 \%$ & $16.2 \%$ & $8.4 \%$ \\
$4.6 \%$ & $4.5 \%$ & $6.3 \%$ & $6.5 \%$ \\
$19.3 \%$ & $6.9 \%$ & $25.3 \%$ & $27.0 \%$ \\
& & & \\
6.68 & 7.00 & 6.77 & 6.93 \\
5.27 & 5.49 & 5.54 & 5.54 \\
0.04 & 0.04 & 0.04 & 0.04 \\
\hline 1062 & 533 & 2058 & 1950 \\
& & & \\
& & & \\
& & \\
& & \\
& &
\end{tabular}

Females

Disability Un- Out of Work employmentabour force

\begin{tabular}{rrrr}
\hline $66.5 \%$ & $76.7 \%$ & $72.2 \%$ & $67.8 \%$ \\
$5.8 \%$ & $5.9 \%$ & $5.7 \%$ & $5.3 \%$ \\
$17.1 \%$ & $11.5 \%$ & $13.8 \%$ & $17.6 \%$ \\
$10.6 \%$ & $5.9 \%$ & $8.3 \%$ & $9.3 \%$ \\
0.02 & 0.03 & 0.01 & 0.02 \\
$17.5 \%$ & $19.4 \%$ & $18.0 \%$ & $25.4 \%$ \\
$20.7 \%$ & $20.8 \%$ & $17.5 \%$ & $24.9 \%$ \\
$21.7 \%$ & $18.1 \%$ & $21.1 \%$ & $19.4 \%$ \\
$19.9 \%$ & $20.1 \%$ & $21.9 \%$ & $17.8 \%$ \\
$20.2 \%$ & $21.5 \%$ & $21.6 \%$ & $12.6 \%$ \\
9.3 & 9.0 & 9.6 & 9.9 \\
$10.2 \%$ & $1.4 \%$ & $14.8 \%$ & $14.1 \%$ \\
& & & \\
11.5 & 11.0 & 11.0 & 12.3 \\
7.1 & 6.7 & 6.6 & 7.4 \\
7.2 & 7.0 & 7.0 & 7.4 \\
7.4 & 10.5 & 8.8 & 7.2 \\
10.7 & 13.5 & 11.9 & 10.1 \\
$29.3 \%$ & $24.0 \%$ & $31.1 \%$ & $43.4 \%$ \\
$44.1 \%$ & $31.2 \%$ & $43.1 \%$ & $64.0 \%$ \\
$1.0 \%$ & $2.1 \%$ & $1.9 \%$ & $2.9 \%$ \\
$24.4 \%$ & $34.4 \%$ & $18.4 \%$ & $25.1 \%$ \\
$19.3 \%$ & $36.5 \%$ & $18.8 \%$ & $17.4 \%$ \\
$4.1 \%$ & $3.5 \%$ & $7.5 \%$ & $2.7 \%$ \\
$4.3 \%$ & $6.3 \%$ & $5.6 \%$ & $4.5 \%$ \\
$46.9 \%$ & $17.4 \%$ & $47.7 \%$ & $47.3 \%$ \\
& & & \\
6.92 & 6.76 & 6.76 & 6.78 \\
5.34 & 5.51 & 5.49 & 5.53 \\
0.04 & 0.04 & 0.04 & 0.04 \\
\hline 898 & 288 & 1805 & 1918 \\
& & & \\
& & & \\
& & & \\
& & & \\
& & & \\
& &
\end{tabular}

Descriptive statistics by end states, by gende 


\begin{tabular}{|c|c|c|c|c|c|c|c|c|}
\hline \multirow[b]{3}{*}{ Individual characteristic } & \multicolumn{2}{|c|}{ Disability } & \multicolumn{2}{|c|}{$\begin{array}{l}\text { Un- } \\
\text { employment }\end{array}$} & \multicolumn{2}{|c|}{$\begin{array}{c}\text { Out of } \\
\text { labour force }\end{array}$} & \multicolumn{2}{|c|}{ W ork } \\
\hline & coeff. & $z$-values & coeff. & $z$-values & coeff. & $z$-values & coeff. & $z$-values \\
\hline & & & & & & & & \\
\hline Unmarried & 0.0271 & 1.1530 & 0.0075 & 0.6190 & -0.0379 & -1.1760 & 0.0034 & 0.1030 \\
\hline Widow(er) & 0.0033 & 0.1190 & -0.0263 & -1.6280 & -0.0609 & -1.6830 & 0.0839 & 2.3680 \\
\hline Divorced & 0.0345 & 1.6190 & 0.0270 & 2.6750 & -0.0042 & -0.1520 & -0.0572 & -1.9640 \\
\hline children $(1=$ Yes $)$ & -0.0689 & -2.2100 & 0.0041 & 0.2880 & 0.0238 & 0.6830 & 0.0410 & 1.2220 \\
\hline Age 62 & 0.0280 & 1.5690 & -0.0106 & -1.0820 & -0.0047 & -0.2090 & -0.0127 & -0.6230 \\
\hline Age 63 & 0.0545 & 3.1010 & 0.0150 & 1.6370 & 0.0344 & 1.5440 & -0.1039 & -4.9590 \\
\hline Age 64 & 0.0429 & 2.3950 & 0.0329 & 3.6530 & 0.0968 & 4.3530 & -0.1726 & -7.9630 \\
\hline Age 65 & 0.0630 & 3.4660 & 0.0342 & 3.6780 & 0.1274 & 5.5130 & -0.2246 & -9.6360 \\
\hline Education & -0.0127 & -5.4230 & -0.0028 & -2.3050 & -0.0055 & -1.9170 & 0.0210 & 7.4880 \\
\hline Civil Servant & -0.0273 & -1.3170 & -0.1488 & -6.3340 & 0.0405 & 1.6490 & 0.1355 & 5.7980 \\
\hline \multicolumn{9}{|l|}{ Income as } \\
\hline Employed & -0.0142 & -7.6280 & -0.0028 & -3.3360 & -0.0026 & -1.6570 & 0.0196 & 12.3370 \\
\hline Unemployed & -0.0061 & -1.5170 & -0.0021 & -1.0580 & -0.0594 & -12.1360 & 0.0676 & 12.6970 \\
\hline Disabled & 0.0457 & 7.7680 & 0.0135 & 4.3820 & 0.0963 & 12.9730 & -0.1555 & -18.4730 \\
\hline \multicolumn{9}{|l|}{ Spouse characteristics } \\
\hline Spouse income & 0.0005 & 0.5920 & 0.0000 & -0.0220 & -0.0034 & -3.0330 & 0.0028 & 2.5930 \\
\hline Spouse benefit receiver & -0.0109 & -0.6750 & -0.0179 & -2.0640 & -0.1437 & -6.7830 & 0.1725 & 8.7040 \\
\hline \multicolumn{9}{|l|}{ Industries } \\
\hline Agri.+Fish. & -0.0101 & -0.3080 & -0.0677 & -2.8430 & -0.0551 & -1.1700 & 0.1330 & 3.1210 \\
\hline Sales, Hotel, Sanitary & 0.0065 & 0.3740 & -0.0292 & -3.3400 & -0.0272 & -1.1440 & 0.0499 & 2.2190 \\
\hline Transport, Commun. & -0.0633 & -3.1060 & -0.1023 & -6.3440 & 0.2326 & 9.8370 & -0.0670 & -2.6330 \\
\hline Dwellings, Financ & -0.0262 & -0.9800 & -0.0423 & -3.0920 & 0.0291 & 0.9130 & 0.0394 & 1.2450 \\
\hline Education, Health & -0.0200 & -1.2690 & -0.0786 & -7.0460 & 0.1014 & 5.1010 & -0.0029 & -0.1470 \\
\hline \multicolumn{9}{|l|}{ Local municipality } \\
\hline Residence density & 0.0035 & 1.3200 & 0.0031 & 2.2000 & -0.0147 & -4.3100 & 0.0082 & 2.3680 \\
\hline Distance to center & -0.0073 & -2.5480 & -0.0009 & -0.5820 & 0.0066 & 1.7160 & 0.0016 & 0.4090 \\
\hline Unempl. Rate & 0.8082 & 1.4740 & 1.4046 & 4.7840 & 3.3985 & 4.7700 & -5.6113 & -7.8580 \\
\hline intercept & -0.1036 & -2.3100 & -0.1505 & -6.0410 & -0.2374 & -4.2070 & 0.4915 & 8.6730 \\
\hline Nbr. of observations & 1062 & & 533 & & 2058 & & 1950 & \\
\hline Pseudo R2 & & 0.102 & & & & & & \\
\hline Log Likelihood & & -6415.0 & & & & & & \\
\hline
\end{tabular}

Table 3 .

Marginal Effects, Multinomial Logit Model, Males 


\begin{tabular}{|c|c|c|c|c|c|c|c|c|}
\hline \multirow[b]{3}{*}{ Individual characteristic } & \multicolumn{2}{|c|}{ Disability } & \multicolumn{2}{|c|}{$\begin{array}{c}\text { Un- } \\
\text { employment }\end{array}$} & \multicolumn{2}{|c|}{$\begin{array}{c}\text { Out of } \\
\text { labour force }\end{array}$} & \multicolumn{2}{|c|}{ W ork } \\
\hline & \multicolumn{2}{|c|}{ coeff. $z$-values } & \multicolumn{2}{|c|}{ coeff. $z$-values } & \multicolumn{2}{|c|}{ coeff. $z$-values } & \multicolumn{2}{|c|}{ coeff. $z$-values } \\
\hline & & & & & & & & \\
\hline Unmarried & -0.0661 & -2.2550 & -0.0144 & -1.2730 & -0.0732 & -2.0060 & 0.1537 & 4.0760 \\
\hline W idow(er) & -0.0561 & -2.6440 & -0.0347 & -3.9550 & -0.1653 & -6.2260 & 0.2561 & 9.4570 \\
\hline Divorced & -0.0386 & -1.6120 & -0.0298 & -2.7200 & -0.1161 & -3.7660 & 0.1844 & 5.8850 \\
\hline children $(1=$ Yes $)$ & 0.0079 & 0.1770 & 0.0202 & 1.4210 & -0.0760 & -1.3070 & 0.0479 & 0.8380 \\
\hline Age 62 & 0.0272 & 1.4790 & 0.0039 & 0.5200 & -0.0065 & -0.2810 & -0.0245 & -1.1020 \\
\hline Age 63 & 0.0438 & 2.3950 & 0.0023 & 0.2960 & 0.0830 & 3.6130 & -0.1290 & -5.6550 \\
\hline Age 64 & 0.0371 & 1.9870 & 0.0090 & 1.1920 & 0.1149 & 4.9780 & -0.1609 & -6.9310 \\
\hline Age 65 & 0.0643 & 3.4070 & 0.0209 & 2.7650 & 0.1640 & 6.8900 & -0.2493 & -10.0610 \\
\hline Education & -0.0134 & -4.8180 & -0.0012 & -1.0010 & 0.0032 & 0.9240 & 0.0115 & 3.3090 \\
\hline Civil Servant & -0.0295 & -1.4570 & -0.0769 & -4.5910 & 0.0700 & 2.8750 & 0.0364 & 1.4530 \\
\hline \multicolumn{9}{|l|}{ Income as } \\
\hline Employed & -0.0245 & -3.4190 & -0.0038 & -1.0950 & 0.0092 & 1.5020 & 0.0191 & 3.0950 \\
\hline Unemployed & 0.0120 & 1.0360 & 0.0100 & 1.7240 & -0.0551 & -5.2010 & 0.0330 & 3.0470 \\
\hline Disabled & 0.0522 & 5.8490 & -0.0041 & -1.0270 & 0.0370 & 3.2120 & -0.0851 & -6.8070 \\
\hline \multicolumn{9}{|l|}{ Spouse characteristics } \\
\hline Spouse income & -0.0020 & -2.6580 & 0.0000 & 0.0920 & -0.0001 & -0.1720 & 0.0021 & 2.6460 \\
\hline Spouse benefit receiver & -0.0904 & -5.1140 & -0.0353 & -5.1100 & -0.1625 & -7.6960 & 0.2882 & 13.1390 \\
\hline \multicolumn{9}{|l|}{ Industries } \\
\hline Agri.+Fish. & -0.1306 & -2.3640 & -0.0080 & -0.4720 & 0.0017 & 0.0310 & 0.1369 & 2.5730 \\
\hline Sales, Hotel, Sanitary & -0.0076 & -0.4260 & 0.0080 & 1.3660 & 0.0746 & 3.1910 & -0.0750 & -3.1970 \\
\hline Transport, Commun. & -0.0176 & -0.5650 & -0.0107 & -0.8040 & 0.2880 & 7.7370 & -0.2597 & -6.0370 \\
\hline Dwellings, Financ & -0.0420 & -1.4100 & -0.0074 & -0.7110 & 0.1434 & 3.9630 & -0.0940 & -2.5000 \\
\hline Education, Health & 0.0066 & 0.4470 & -0.0490 & -7.1590 & 0.0939 & 4.7660 & -0.0515 & -2.6510 \\
\hline \multicolumn{9}{|l|}{ Local municipality } \\
\hline Residence density & 0.0072 & 2.5270 & -0.0007 & -0.6470 & -0.0077 & -2.2120 & 0.0013 & 0.3640 \\
\hline Distance to center & -0.0097 & -3.1790 & 0.0014 & 1.1090 & 0.0040 & 1.0140 & 0.0043 & 1.0490 \\
\hline Unempl. Rate & 0.8332 & 1.4630 & 0.8834 & 3.8460 & 2.3648 & 3.2520 & -4.0814 & -5.3980 \\
\hline intercept & -0.1307 & -2.8450 & -0.0547 & -2.7530 & -0.0443 & -0.7660 & 0.2297 & 3.8460 \\
\hline Nbr. of observations & 898 & & 288 & & 1805 & & 1918 & \\
\hline Pseudo R2 & & 0.070 & & & & & & \\
\hline Log Likelihood & & -5535.6 & & & & & & \\
\hline
\end{tabular}

Table 4 .

Marginal Effects, Multinomial Logit Model, Females 


\begin{tabular}{|c|c|c|}
\hline & Males & Females \\
\hline Family (unmarried, widow(er), divorced & $1.14[3]$ & $2.83[3]$ \\
\hline children & $4.19[1]^{*}$ & $0.07[1]$ \\
\hline Age (age 62, age 63, age 64, age 65) & $5.97[4]$ & $5.68[4]$ \\
\hline Education & $12.95[1]^{*}$ & $15.07[1]^{*}$ \\
\hline Civil servan & $12.22[1]^{\star}$ & $2.81[1]$ \\
\hline Income as (employed, unemployed, disabled & $45.76[3]^{*}$ & $34.04[3]^{*}$ \\
\hline Income as employed & $28.82[1]^{\star}$ & $6.13[1]^{*}$ \\
\hline Income as unemployed & $0.76[1]$ & $0.02[1]$ \\
\hline Income as disabled & $22.46[1]^{\star}$ & $31.58[1]^{*}$ \\
\hline Spouse income & $0.27[1]$ & $6.22[1]^{*}$ \\
\hline Spouse benefit receivel & $0.14[1]$ & $7.99[1]^{\star}$ \\
\hline Industries & $11.15[5]^{*}$ & $29.05[5]^{*}$ \\
\hline Local municipality (Residence density, distance to cer & $4.48[2]$ & $11.84[2]^{*}$ \\
\hline & $0.87[1]$ & $0.01[1]$ \\
\hline
\end{tabular}

Table 5. Testing the similarity of marginal effects i Disability and Unemployment ([df]) 